Article

\title{
Cuboid Packed-Beds as Chemical Reactors?
}

\section{Raja Ghosh}

Department of Chemical Engineering, McMaster University, 1280 Main Street West, Hamilton, ON L8S 4L7, Canada; rghosh@mcmaster.ca; Tel.: +1-905-525-9140 (ext. 27415)

Received: 12 April 2018; Accepted: 23 April 2018; Published: 1 May 2018

\begin{abstract}
Columns are widely used as packed-bed or fixed-bed reactors in the chemical process industry. Packed columns are also used for carrying out chemical separation techniques such as adsorption, distillation, extraction and chromatography. A combination of the variability in flow path lengths, and the variability of velocity along these flow paths results in significant broadening in solute residence time distribution within columns, particularly in those having low bed height to diameter ratios. Therefore, wide packed-column reactors operate at low efficiencies. Also, for a column of a particular bed height, the ratio of heat transfer surface area to reactor volume varies inversely as the radius. Therefore, with wide columns, the available heat transfer area could become a limiting factor. In recent papers, box-shaped or cuboid packed-bed devices have been proposed as efficient alternatives to packed columns for carrying out chromatographic separations. In this paper, the use of cuboid packed-beds as reactors for carrying out chemical and biochemical reactions has been proposed. This proposition is primarily supported in terms of advantages resulting from superior system hydraulics and narrower residence time distributions. Other potential advantages, such as better heat transfer attributes, are speculated based on geometric considerations.
\end{abstract}

Keywords: packed-bed reactor; packed column; cuboid packed-bed; chemical reactor; residence time distribution; heat transfer

\section{Introduction}

Packed-bed or fixed-bed reactors are ubiquitous in the chemical process industry [1-3]. With the increasing popularity of flow chemistry-based synthesis, their use is likely to increase [4-6]. A column is the most common configuration for a packed-bed reactor. It is a cylindrical vessel within which a bed of particles is tightly held in place under compression (see Figure 1). In certain specialized forms of packed-beds, such as monoliths $[7,8]$, the particles are fused together. Packed columns are also used for chemical separation techniques such as adsorption, distillation, extraction and chromatography [9-12].

A packed-column reactor generally facilitates contact between the surface of catalyst particles and reactant/s present in the fluid flowing through it. The most common example of the use of such catalytic packed-column reactors is ammonia synthesis. Columns packed with inert material could also be used to bring about intimate contact between reactants in a simple and continuous flow-through mode. In a separation process, the solid material comprising the packed column is generally the separation media, e.g., an adsorbent, being used to separate a solute of interest. Packed columns are also used to increase the interfacial area between immiscible fluids in processes such as distillation and extraction.

The residence time distribution or RTD is an important attribute in packed-bed reactors [13-15]. By the rule of thumb, the wider the column, and the poorer (i.e., the broader) is the RTD. Therefore, wider columns are less efficient than longer columns. Also, with a column of a particular bed height, the heat transfer surface area to reactor volume ratio (i.e., specific surface area, excluding the headers) varies inversely as the radius. Therefore, when columns with large cross-sectional areas are used, 
the available heat transfer area could become a limiting factor [16-18]. Where this is the case, multi-tube packed-column reactors are commonly used [19-22]. While this multi-tube configuration increases heat-transfer, there are penalties in the form of design complexity, and higher equipment cost.

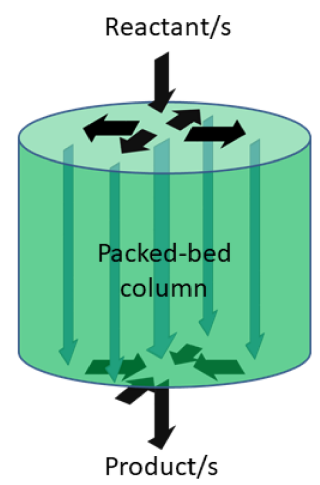

Figure 1. Idealized flow paths in a packed column.

Chromatography is traditionally carried out using packed columns. In recent papers from my group, we have proposed the use of box-shaped or cuboid packed-bed devices as alternative to columns, for carrying out chromatographic separation of proteins [23-26]. The design of these cuboid packed-bed devices was inspired by laterally fed membrane chromatography (or LFMC) devices [27-31], also developed in recent years in my research group. A diagrams of a cuboid packed-bed device is shown in Figure 2. A set of lateral flow channels similar to those utilized in LFMC devices [27-31] are used to distribute the feed liquid into the cuboid packed-bed and collect the effluent liquid emerging from it on the other side. Such flow arrangement ensures uniformity in solute flow path lengths, which in turn contributes towards the narrowing of the solute RTD within the device [24,29]. Figures 1 and 2 show images of a packed column and a cuboid packed-bed respectively, in each case, showing the idealized flow-paths within these devices. As mentioned earlier, a combination of variability in the flow path lengths and variability of velocity along these flow paths results in a significant broadening in solute RTD within a column [23]. This contributes towards peak broadening and poor peak-resolution in multi-component separation. By contrast, the flow path lengths within a cuboid packed-bed are fairly uniform and the velocities along these do not vary that significantly [23]. The cuboid packed-bed devices described in our papers outperformed their corresponding equivalent chromatography columns (i.e., packed with same media, and having the same bed height and area of cross-section) in terms of multiple separation metrics such as the number of theoretical plates, peak shape, peak width, peak asymmetry, and resolution in multi-component protein separation [23-26]. The dispersion effects in these cuboid packed-bed devices were significantly lower than those in their equivalent columns as evident from their greater numbers of theoretical plates per unit bed height. Based on the above considerations, could it be assumed that box-shaped or cuboid packed-bed reactors would outperform packed-column reactors, at least in terms of their hydraulic properties and RTD attributes?

This paper proposes the use of cuboid packed-beds as reactors for carrying out chemical and biochemical reactions. The rationale this is provided in terms of advantages resulting from superior system hydraulics and the resultant narrower RTD. The residence time distribution predictions are based on mathematical models discussed in our earlier papers [24,29]. Other potential advantages, such as superior heat transfer attributes are speculated based on geometric considerations. 


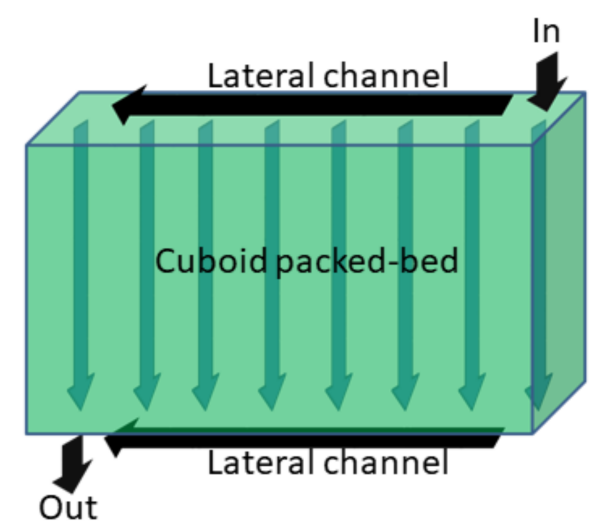

Figure 2. Idealized flow paths in a cuboid packed-bed.

\section{Materials and Methods}

Sodium chloride was purchased from Sigma-Aldrich (St. Louis, MO, USA). Sodium chloride solution was prepared using water obtained from a SIMPLICITY 185 water purification unit Millipore (Molsheim, France). All solutions were micro-filtered and degassed prior to use using PVDF micro-filter (VVLP04700, $0.1 \mu \mathrm{m}$ pore size, Millipore, Billerica, MA, USA). HiTrap Capto S (5 mL, product number 17-5441-2) columns, and Capto $S$ (product number 17-5441-01) chromatographic media were purchased from GE Healthcare Biosciences, QC, Canada. The HiTrap Capto S column was used as the surrogate packed-column reactor while a custom designed cuboid packed-bed device filled with Capto $S$ resin particles served as the surrogate cuboid packed-bed reactor. The basic design of the cuboid packed-bed devices has been described in our previous papers [23-26]. The central housing for the cuboid packed-bed was made of polyvinyl chloride (PVC). The upper and lower plates were made of acrylic. The lateral channels engraved in the plates were pillared for efficient flow distribution and collection respectively. The dimensions of the cuboid packed-bed were respectively $25 \mathrm{~mm}$ (length) $\times 8 \mathrm{~mm}$ (width) $\times 25 \mathrm{~mm}$ (height), the effective bed volume being $5 \mathrm{~mL}$. The packed-bed was separated from the lateral channels using nylon meshes (0.002 inch opening, product number 9318T48, McMaster Carr, Chicago, IL, USA) for retaining and holding the chromatographic media in place.

An AKTA prime liquid chromatography system (GE Healthcare Biosciences, Quebec, QC, Canada) was used for salt tracer experiments. E-curve type profiles for the packed column and the cuboid packed-bed device were obtained using $0.8 \mathrm{M}$ sodium chloride as tracer and $0.4 \mathrm{M}$ sodium chloride as base solution. A $0.1 \mathrm{~mL}$ sample loop was used for injecting the tracer pulse for characterizing the hydraulics of the column and the cuboid packed-bed.

\section{Results and Discussion}

In a previous paper [23], the performance of a chromatographic column having $9 \mathrm{~mL}$ bed volume (30 mm diameter and $12.7 \mathrm{~mm}$ bed height) and packed with Capto $\mathrm{S}$ media was compared with an equivalent cuboid packed-bed ( $58.9 \mathrm{~mm}$ length $\times 12 \mathrm{~mm}$ width $\times 12.7 \mathrm{~mm}$ height). At a flow rate of $5 \mathrm{~mL} / \mathrm{min}$ which corresponded to a superficial velocity of $42.4 \mathrm{~cm} / \mathrm{h}$, the number of theoretical plates per meter were found to be 2628 and 4651 respectively, for the column and the cuboid packed-bed. To verify whether such difference was due to flow maldistribution within the column, the RTD within the column and the cuboid packed-bed device were simulated using the using the methods described in our previous papers [24,29]. Figure 3 shows the RTD within the column as function of dimensionless radius $(r / R)$ and dimensionless column volume $\left(V / V_{T}\right)$ at a superficial velocity of $42.4 \mathrm{~cm} / \mathrm{h}$. The radial distance step used in the simulation was $0.001 \mathrm{~cm}$. The shortest residence time corresponded to $r=0$, i.e., the center of the column, and the value increased significantly towards the periphery. This was consistent with the idealized flow paths picturized in Figure 1. In the top header, the liquid flowed in a radially outward direction while in the lower header, it flowed in a radially 
inward direction. This flow pattern resulted in significant variability in the path lengths, i.e., a flow path closer to the center was significantly shorter than one closer to the periphery. Also, as discussed in a previous paper [23], the radial velocity in the top header decreased very significantly in an outward direction due to an increase in available cross-sectional area, and the loss of liquid due to entry in to the packed-bed.

$$
\frac{d v_{r}}{d r}=-\left(\frac{v_{r}}{r}+\frac{v_{s}}{h}\right)
$$

In the lower header, the radial velocity increased in an inward direction due to a decrease in available cross-sectional area and cumulative collection of liquid from the packed-bed. Quite clearly, the increased transit time in the column headers for fluid elements traversing the peripheral regions of the column contributed significantly to the increase in residence time. Both profiles shown in Figure 3 indicated the same trend, i.e., the residence time increased very significantly closer to the column periphery. However, this increase was a bit more pronounced when the residence time was plotted versus $\left(V / V_{T}\right)$. This reflected the fact that in a column, more media was located towards the periphery than near the center. Figure 4 shows a plot of $\left(V / V_{T}\right)$ versus $(r / R)$ which indicated that $50 \%$ of the media existed in the outer $29 \%$ radial locations of the column. Hence, the increased residence time closer to the periphery of the column affected a very significant volume fraction of media packed within the column.

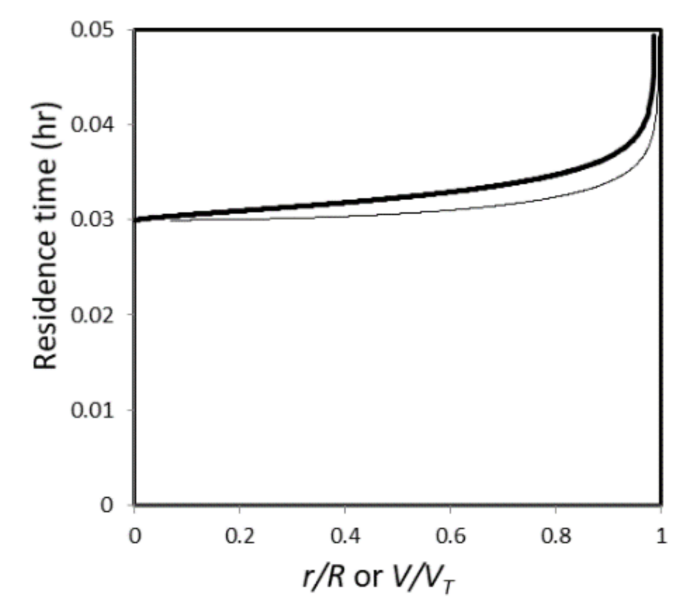

Figure 3. Residence time within a column as function of dimensionless radius $(r / R)$ and dimensionless volume $\left(V / V_{T}\right)$ (media: Capto $Q$, dimensions: $30 \mathrm{~mm}$ diameter and $12.7 \mathrm{~mm}$ bed height, bed volume: $9 \mathrm{~mL}$, flow rate: $5 \mathrm{~mL} / \mathrm{min}$, superficial velocity $=42 \mathrm{~cm} / \mathrm{h}$ ).

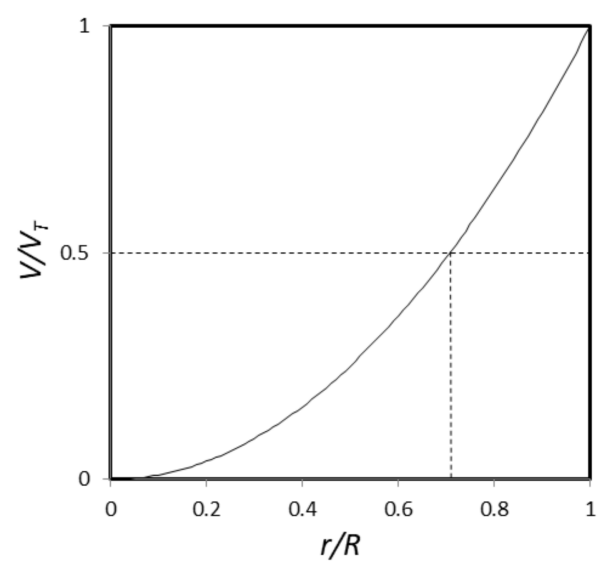

Figure 4. Plot of dimensionless volume $\left(V / V_{T}\right)$ versus dimensionless radius $(r / R)$. 
Figure 5 shows the RTD within the cuboid packed-bed device as function of dimensionless length $(z / l)$. The lateral distance step used in the simulation was $0.001 \mathrm{~cm}$. In a recent paper (24) it has been shown that the residence time as function of length within a cuboid packed-bed could be obtained by:

$$
\tau=\left[\frac{h_{B}}{v_{S}}\right]+\left[\frac{2 z}{2 v_{0}-z\left|\frac{d v_{U}}{d z}\right|}\right]+\left[\frac{2(l-z)}{2 v_{0}-(l-z)\left|\frac{d v_{U}}{d z}\right|}\right]
$$

When $\left|\frac{d v_{U}}{d z}\right|$ is small:

$$
\tau \cong \frac{h_{B}}{v_{S}}+\frac{l}{v_{0}}
$$

Equation (3) implies that when the change in velocity within the lateral channels of the cuboid packed-bed is small, the residence time is largely independent of location. Figure 5 shows that for the cuboid packed-bed device under consideration [23], the residence time was slightly lower at the mid-point of the device. However, the difference in residence time between the mid-point and the ends was negligible compared to that observed with the packed column. From Equation (2), it could be shown that the minimum residence time corresponding to the mid-point of the cuboid packed-bed device could be obtained by [24]:

$$
\tau_{\min }=\left[\frac{h_{B}}{v_{S}}\right]+\left[\frac{2 l}{2 v_{0}-\frac{l}{2}\left|\frac{d v_{U}}{d z}\right|}\right]
$$

Likewise, the maximum residence time corresponding to the ends could be obtained by [24]:

$$
\tau_{\max }=\left[\frac{h_{B}}{v_{S}}\right]+\left[\frac{2 l}{2 v_{0}-l\left|\frac{d v_{U}}{d z}\right|}\right]
$$

For the optimum functioning of a cuboid packed-bed device, the difference between the maximum and minimum residence time should be as small as possible [24]:

$$
\left|\tau_{\max }-\tau_{\min }\right|=\left[\frac{2 l}{2 v_{0}-l\left|\frac{d v_{u}}{d z}\right|}\right]-\left[\frac{2 l}{2 v_{0}-\frac{l}{2}\left|\frac{d v_{u}}{d z}\right|}\right]
$$

Tracer experiments using sodium chloride solution were carried out with the $5 \mathrm{~mL}$ HiTrap Capto $S$ column (i.e., the surrogate packed-column reactor) and the $5 \mathrm{~mL}$ custom designed cuboid packed-bed device filled with Capto $S$ resin particles (i.e., the surrogate cuboid packed-bed reactor). These experiments were performed in triplicate. Figure 6 shows representative salt tracer peaks obtained from these experiments which were carried at $4 \mathrm{~mL} / \mathrm{min}$ flow rate $(150 \mathrm{~cm} / \mathrm{h}) \mathrm{using} 0.4 \mathrm{M}$ sodium chloride as mobile phase and $100 \mu \mathrm{L}$ of $0.8 \mathrm{M}$ sodium chloride solution as the tracer pulse (i.e., $2 \%$ of the packed-bed volume). The peak obtained with the cuboid packed-bed device was higher, sharper and more symmetric than that obtained with the column. The calculated theoretical plate data $(N)$ obtained from these are summarized in Table 1 . The number of theoretical plates was calculated using the following equation [32]:

$$
N=5.545\left(t_{R} / w_{0.5}\right)^{2}
$$

The results shown in Figure 6 and Table 1 clearly demonstrate that the cuboid packed-bed device had vastly superior hydraulic attributes than the equivalent packed column. For the same bed height, the cuboid packed-bed had 3.8 times the number of theoretical plates. These new experimental results are consistent with the RTD results shown in Figures 3 and 5. Overall, these results suggest that a reactor based on the cuboid packed-bed design would perform better than its equivalent packed 
column, at least in terms of the hydraulic properties and RTD. Future studies will involve detailed analysis of E-curves and F-curves obtained from such reactors. Also, the experiments discussed above were carried out using small reactors (i.e., $5 \mathrm{~mL}$ bed volume). Experimental work based on $200 \mathrm{~mL}$ scale reactors are currently being carried out in my laboratory. Computational fluid dynamics (CFD) studies which allow the study of larger reactors through simulations are also being carried out in parallel.

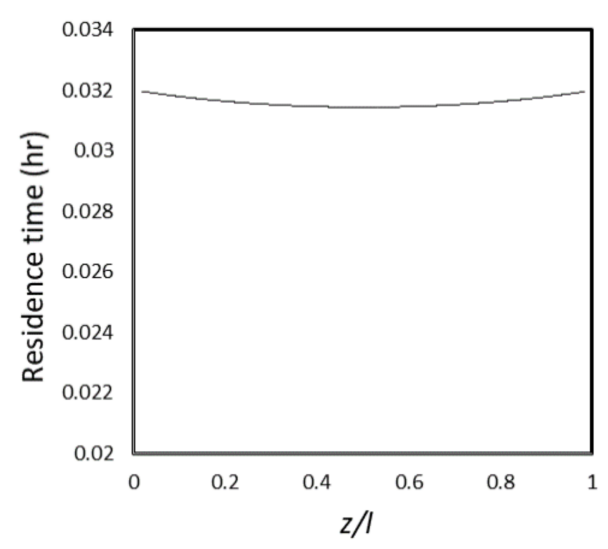

Figure 5. Residence time within a cuboid packed-bed as function of dimensionless length $(z / l)$ (media: Capto $Q$, dimensions: $58.9 \mathrm{~mm}$ length $\times 12 \mathrm{~mm}$ width $\times 12.7 \mathrm{~mm}$ bed height, bed volume: $9 \mathrm{~mL}$, Flow rate: $5 \mathrm{~mL} / \mathrm{min}$, superficial velocity $=42 \mathrm{~cm} / \mathrm{h}$ ).

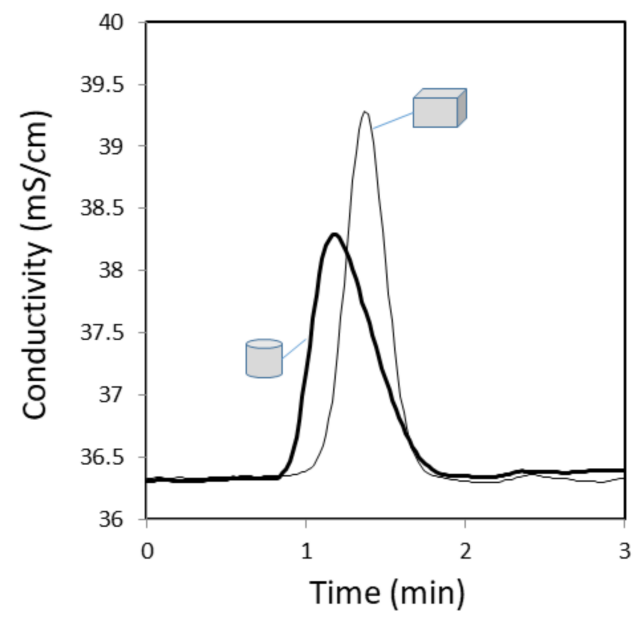

Figure 6. Salt tracer peaks obtained using the surrogate packed-column reactor and the surrogate cuboid packed-bed reactor (bed volume: $5 \mathrm{~mL}$, bed height $25 \mathrm{~mm}$, flow rate: $4 \mathrm{~mL} / \mathrm{min}$, superficial velocity: $150 \mathrm{~cm} / \mathrm{h}$, media: Capto $\mathrm{S}$, mobile phase: $0.4 \mathrm{M}$ sodium chloride, tracer: $0.8 \mathrm{M}$ sodium chloride, tracer volume: 1 microliters).

Table 1. Number of theoretical plates in the surrogate packed-column reactor and the surrogate cuboid packed-bed reactor (bed volume: $5 \mathrm{~mL}$, bed height $25 \mathrm{~mm}$, flow rate: $4 \mathrm{~mL} / \mathrm{min}$, superficial velocity: $150 \mathrm{~cm} / \mathrm{h}$, media: Capto S, mobile phase: $0.4 \mathrm{M}$ sodium chloride, tracer: $0.8 \mathrm{M}$ sodium chloride, tracer volume: 1 microliters).

\begin{tabular}{cc}
\hline Device & N \\
\hline Packed column & 35 \\
Cuboid packed-bed & 133 \\
Error: $\pm 5 \%$ & \\
\hline
\end{tabular}


The design features of the cuboid packed-bed device also provide certain potential advantages from a heat transfer perspective. With a packed column of a given bed height, the heat transfer area per unit reactor volume (excluding the headers) varies inversely with the diameter, i.e., the larger the reactor diameter, the lower is the specific heat transfer area (HTA). This implies that removal or addition of heat to a packed column with a large diameter for endothermic and exothermic reactions respectively would be challenging. By contrast, the HTA of a cuboid packed-bed device could be changed in a very flexible manner by changing the length to width (L/W) ratio, to increase or decrease the values of HTA as required. To make an objective comparison, the HTA of a cuboid packed-bed device was compared with that of a packed column having the same bed height and bed-volume. For a packed column, the HTA is fixed based on the diameter. Figure 7 shows a plot of the $\left(\mathrm{HTA}_{\text {cuboid }} / \mathrm{HTA}_{\text {column }}\right)$ ratio for the two reactors as function of the $(\mathrm{L} / \mathrm{W})$ ratio of the cuboid packed-bed device. The minimum $\left(\mathrm{HTA}_{\text {cuboid }} / \mathrm{HTA}_{\text {column }}\right)$ ratio corresponded to an $(\mathrm{L} / \mathrm{W})$ ratio of 1 , i.e., when the cuboid packed-bed device had a square cross-sectional area. As the $(\mathrm{L} / \mathrm{W})$ ratio was increased, the $\left(\mathrm{HTA}_{\text {cuboid }} / \mathrm{HTA}_{\text {column }}\right)$ ratio could be increased quite significantly. Therefore, a cuboid packed-bed reactor would have a significant advantage over a packed column for conducting endothermic and exothermic reactions.

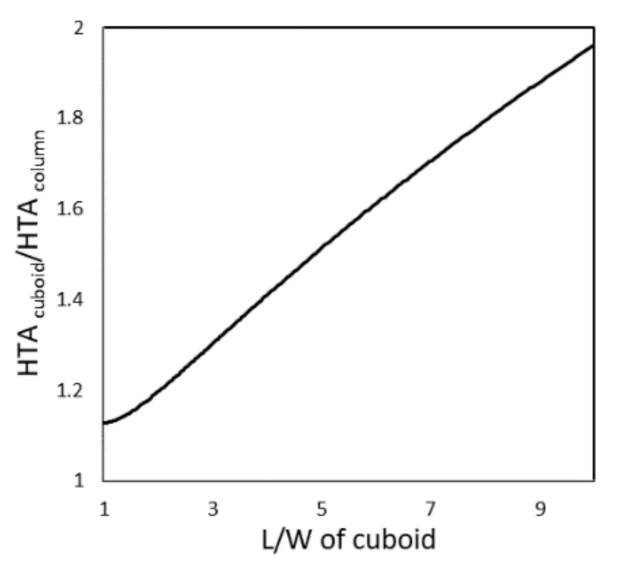

Figure 7. $\left(\mathrm{HTA}_{\text {cuboid }} / \mathrm{HTA}_{\text {column }}\right)$ ratio as function of the $(\mathrm{L} / \mathrm{W})$ ratio of a cuboid packed-bed reactor.

The heat transfer advantage of the cuboid packed-bed device over a packed column could also be hypothesized from a heat transfer distance perspective. Heat transfer distance is a vital factor determining thermal gradients within packed-beds, i.e., the greater the distance, the greater is the likelihood of temperature variation. As shown in Figure 8, the maximum heat transfer distance (MHTD) for a packed column corresponded to its radius. On the other hand, the average heat transfer distance (AHTD) corresponded to $29 \%$ of the radius, since $50 \%$ of the packed material existed within the zone extending up to $71 \%$ of the radius from the center. Therefore, both MHTD and AHTD for a packed column varied directly with the diameter, i.e., the greater the diameter, the greater these heat transfer distances. Therefore, for a packed column having a particular bed height and bed volume, both MHTD and AHTD are fixed. Once again, these heat transfer distances for a cuboid packed-bed could be adjusted in a flexible manner by changing the $(\mathrm{L} / \mathrm{W})$ ratio. To make an objective comparison, the MHTD and AHTD of a cuboid packed-bed device were compared with those of a packed column having the same bed height and the same bed volume. With the cuboid packed-bed device, the MHTD was equal to half the width while the AHTD was equal to one fourth the width. Figure 8 shows a plot of the MHTD and AHTD ratios for the two reactors (cuboid/column) as function of the (L/W) ratio of the cuboid packed-bed device. The MHTD of the cuboid packed-bed device was consistently lower at all values of $(\mathrm{L} / \mathrm{W})$. The AHTD was greater with cuboid packed-bed device for $(\mathrm{L} / \mathrm{W})$ values lower than 2.4 but was lower are greater values of $(\mathrm{L} / \mathrm{W})$. Once again, these results suggest that a cuboid packed-bed reactor would have a significant advantage over a packed column for conducting endothermic and exothermic reactions. 

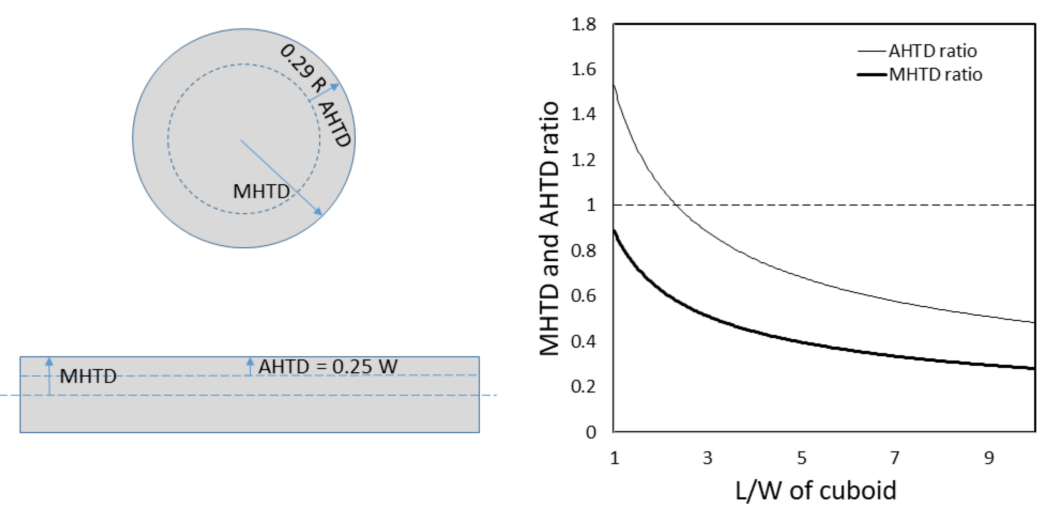

Figure 8. $\left(\mathrm{MHTD}_{\text {cuboid }} / \mathrm{MHTD}_{\text {column }}\right)$ and $\left(\mathrm{AHTD}_{\text {cuboid }} / \mathrm{AHTD}_{\text {column }}\right)$ ratios as function of the $(\mathrm{L} / \mathrm{W})$ ratio of a cuboid packed-bed reactor.

\section{Conclusions}

The above discussion supports the basic proposition of this paper, i.e., cuboid packed-beds could potentially be used as reactors for carrying out chemical and biochemical reactions. The principal rationale behind this proposition is that the narrower RTD of the cuboid packed-bed makes it better than a packed column for carrying out chemical reaction. The superior RTD attributes of the cuboid packed-bed were demonstrated using mathematical models and new experimental data obtained using surrogate packed column and cuboid packed-bed reactors. In addition to superior RTD attributes, the cuboid packed-bed could potentially also have superior heat transfer attributes, relevant for conducting exothermic and endothermic reactions. These potential advantages, were speculated-based purely on geometric considerations. For packed columns of a given bed height, the heat transfer area per unit reactor volume varies inversely with the diameter. Therefore, if a packed column with a large diameter is to be used for conducting endothermic or exothermic reactions, removal or addition of heat would be challenging. By contrast, the specific heat transfer area of a cuboid packed-bed device could be changed in a very flexible manner by changing the length to width ratio. The cuboid packed-bed also compares favorably in terms of lower heat transfer distances. Therefore, a cuboid packed-bed reactor could potentially have significant advantages over a packed column, also from a heat transfer perspective.

\section{Patents}

CHROMATOGRAPHY DEVICE AND METHOD FOR FILTERING A SOLUTE FROM A FLUID R Ghosh-US Patent App. 15/616, 333, 2017.

Funding: This research was funded by the Natural Sciences and Engineering Research Council (NSERC) of Canada, and the Ontario Research Fund-Research Excellence Programme.

Acknowledgments: This work is supported by the natural Science and Engineering Research Council (NSERC) of Canada and the Ontario Research Fund-Research Excellence (ORF-RE) Program. The Author thanks Paul Gatt (department of Chemical Engineering, McMaster University) for fabricating the cuboid packed-bed devices used in this study based on design provided by the author.

Conflicts of Interest: The author declares no conflict of interest.

\section{Notation}

$\begin{array}{ll}v_{r} & \text { Radial velocity }(\mathrm{m} / \mathrm{s}) \\ r & \text { Dimension in radial direction }(\mathrm{m}) \\ v_{S} & \text { Superficial (or linear) velocity }(\mathrm{m} / \mathrm{s}) \\ h & \text { Header height }(\mathrm{m}) \\ V & \text { Volume }\left(\mathrm{m}^{3}\right) \\ V_{T} & \text { Total volume of packed column }\left(\mathrm{m}^{3}\right)\end{array}$


$R \quad$ Total radius of packed column (m)

$\tau \quad$ Residence time (s)

$h_{B} \quad$ Bed height $(\mathrm{m})$

$z \quad$ Dimension along length of cuboid packed-bed (m)

$v_{0} \quad$ Inlet velocity in upper lateral channel $(\mathrm{m} / \mathrm{s})$

$v_{U} \quad$ Velocity in upper lateral channel $(\mathrm{m} / \mathrm{s})$

$l \quad$ Length of cuboid packed-bed (m)

$\tau_{\min } \quad$ Minimum residence time (s)

$\tau_{\max } \quad$ Maximum residence time (s)

$N \quad$ Number of theoretical plates (-)

$t_{R} \quad$ Retention time (s)

$w_{0.5} \quad$ Peak width at half height (s)

\section{References}

1. Andrigo, P.; Bagatin, R.; Pagani, G. Fixed bed reactors. Catal. Today 1999, 52, 197-221. [CrossRef]

2. Chica, A.; Corma, A.; Dómine, M.E. Catalytic oxidative desulfurization (ODS) of diesel fuel on a continuous fixed-bed reactor. J. Catal. 2006, 242, 299-308. [CrossRef]

3. Yuan, T.; Tahmasebi, A.; Yu, J. Comparative study on pyrolysis of lignocellulosic and algal biomass using a thermogravimetric and a fixed-bed reactor. Bioresour. Technol. 2015, 175, 333-341. [CrossRef] [PubMed]

4. Szloszár, A.; Mándity, I.M.; Fülöp, F. Sustainable synthesis of N-methylated peptides in a continuous-flow fixed bed reactor. J. Flow Chem. 2018, 8, 21-27.

5. Brzozowski, M.; O’Brien, M.; Ley, S.V.; Polyzos, P. Flow Chemistry: Intelligent processing of gas-liquid transformations using a tube-in-tube reactor. Acc. Chem. Res. 2015, 48, 349-362. [CrossRef] [PubMed]

6. Adamo, A.; Beingessner, R.L.; Behnam, M.; Chen, J.; Jamison, T.F.; Jensen, K.F.; Monbaliu, J.C.M.; Myerson, A.S.; Revalor, E.M.; Snead, D.R.; et al. On-demand continuous-flow production of pharmaceuticals in a compact, reconfigurable system. Science 2016, 352, 61-67. [CrossRef] [PubMed]

7. Sauer, M.L.; Ollis, D.F. Acetone oxidation in a photocatalytic monolith reactor. J. Catal. 1994, 149, 81-91. [CrossRef]

8. Wang, Y.; Sun, G.; Dai, J.; Chen, G.; Morgenstern, J.; Wang, Y.; Kang, S.; Zhu, M.; Das, S.; Cui, L.; et al. A high-performance, low-tortuosity wood-carbon monolith reactor. Adv. Mater. 2017, 29, 1604257. [CrossRef] [PubMed]

9. Lin, C.-C.; Liu, W.-T.; Tan, C.-S. Removal of carbon dioxide by absorption in a rotating packed-bed. Ind. Eng. Chem. Res. 2003, 42, 2381-2386. [CrossRef]

10. Bader, A.J.; Afacan, A.; Sharp, D.; Chuang, K.T. Effect of liquid-phase properties on separation efficiency in a randomly packed distillation column. Can. J. Chem. Eng. 2015, 93, 1119-1125. [CrossRef]

11. Lesellier, E.; West, C. The many faces of packed column supercritical fluid chromatography-A critical review. J. Chromatogr. A 2015, 1382, 2-46. [CrossRef] [PubMed]

12. West, C.; Khalikova, M.A.; Lesellier, E.; Héberger, K. Sum of ranking differences to rank stationary phases used in packed column supercritical fluid chromatography. J. Chromatogr. A 2015, 1409, 241-250. [CrossRef] [PubMed]

13. Guo, K.; Guo, F.; Feng, Y.; Chen, J.; Zheng, C.; Gardner, N.C. Synchronous visual and RTD study on liquid flow in rotating packed-bed contactor. Chem. Eng. Sci. 2000, 55, 1699-1706. [CrossRef]

14. Yang, C.; Teixeira, A.R.; Si, Y.; Born, S.; Lin, H.; Song, Y.L.; Peer, M.; Martin, B.; Schenkel, B.; Jensen, K.F. Catalytic hydrogenation of N-4-nitrophenyl nicotinamide in a micro-packed-bed reactor. Green Chem. 2018, 20, 886-893. [CrossRef]

15. Dadgar, F.; Venvik, H.J.; Pfeifer, P. Application of hot-wire anemometry for experimental investigation of flow distribution in micro-packed-bed reactors for synthesis gas conversion. Chem. Eng. Sci. 2018, 177, 110-121. [CrossRef]

16. Dixon, A.G.; Cresswell, D.L. Theoretical prediction of effective heat transfer parameters in packed-beds. AIChE J. 1979, 25, 663-676. [CrossRef] 
17. Mears, D.E. Tests for transport limitations in experimental catalytic reactors. Ind. Eng. Chem. Proc. Des. Dev. 1971, 10, 541-547. [CrossRef]

18. Nijemeisland, M.; Dixon, A.G. Comparison of CFD simulations to experiment for convective heat transfer in a gas-solid fixed bed. Chem. Eng. J. 2001, 82, 231-246. [CrossRef]

19. Olbert, G.; Corr, F.; Reuter, P.; Wambach, L.; Hammon, U. Multi-Tube Fixed-Bed Reactor, Especially for Catalytic Gas Phase Reactions. U.S. Patent 7,226,567, 5 June 2007.

20. Sugiyama, M.; Ando, Y.; Taniguchi, Y. Fixed Bed Multitube Reactor. U.S. Patent 7,588,739, 15 September 2009.

21. Westerman, D.; Schrauwen, F.J.M. Multitube Reactor. U.S. Patent 4,894,205, 16 January 1990.

22. Jiang, B.; Hao, L.; Zhang, L.; Sun, Y.; Xiao, X. Numerical investigation of flow and heat transfer in a novel configuration multi-tubular fixed bed reactor for propylene to acrolein process. Heat Mass Transf. 2015, 51, 67-84. [CrossRef]

23. Ghosh, R. Using a box instead of a column for process chromatography. J. Chromatogr. A 2016, 1468, $164-172$. [CrossRef] [PubMed]

24. Ghosh, R.; Chen, G. Mathematical modelling and evaluation of performance of cuboid packed-bed devices for chromatographic separations. J. Chromatogr. A 2017, 1515, 138-145. [CrossRef] [PubMed]

25. Chen, G.; Ghosh, R. Effects of process parameters on the efficiency of chromatographic separations using a cuboid packed-bed device. J. Chromatogr. B 2018, in press. [CrossRef] [PubMed]

26. Chen, G.; Gerrior, A.; Ghosh, R. Feasibility study for high-resolution multi-component separation of protein mixture using a cation-exchange cuboid packed-bed device. J. Chromatogr. A 2018, 1549, 25-30. [CrossRef] [PubMed]

27. Madadkar, P.; Wu, Q.; Ghosh, R. A laterally-fed membrane chromatography module. J. Membr. Sci. 2015, 487, 173-179. [CrossRef]

28. Madadkar, P.; Nino, S.L.; Ghosh, R. High-resolution, preparative purification of PEGylated protein using a laterally-fed membrane chromatography device. J. Chromatogr. B 2016, 1035, 1-7. [CrossRef] [PubMed]

29. Ghosh, R.; Madadkar, P.; Wu, Q. On the workings of laterally-fed membrane chromatography. J. Membr. Sci. 2016, 516, 26-32. [CrossRef]

30. Madadkar, P.; Umatheva, U.; Hale, G.; Durocher, Y.; Ghosh, R. Ultrafast separation and analysis of monoclonal antibody aggregates using membrane chromatography. Anal. Chem. 2017, 89, 4716-4720. [CrossRef] [PubMed]

31. Madadkar, P.; Sadavarte, R.; Butler, M.; Durocher, Y.; Ghosh, R. Preparative separation of monoclonal antibody aggregates by cation-exchange laterally-fed membrane chromatography. J. Chromatogr. B 2017, 1055, 158-164. [CrossRef] [PubMed]

32. Moldoveanu, S.C.; David, V. Essentials in Modern HPLC Separations; Elsevier: Amsterdam, The Netherlands, 2013 ; p. 63. 